\title{
Egypt towards Better Health and Well-being
}

Rehab A. Rayan

Good health and well-being are essential for a stronger society and a fundamental human right. Ill health is evidently associated with poverty. Egypt targets improving health services, despite the scarcity of financial resources, a growing population, and the need for better governance. The Ministry of Health has identified strategic objectives to be achieved by 2030 , which primarily targets improving the health of citizens by providing and enhancing primary healthcare via awareness and preventive measures; and achieving comprehensive healthcare coverage for all citizens.

Recently, Egypt has a new success story in managing hepatitis $\mathrm{C}$ virus (HCV). Egypt was among the top countries with a highly prevalent HCV. Eliminating HCV faced several obstacles including shortage in global funding for treatment, late diagnosis, insufficient data, and poor screening. Treating HCV in Egypt has been nationally prioritized with the rise of the highly effective directacting antivirals. Egypt implemented a pattern of care, which could aid other similar countries in combating HCV.

Moreover, In December 2017, followed by May 2018, the universal health insurance law and its executive regulations were issued successively in Egypt. Under the new law, health care will be accessible for all citizens and expanded to the estimated $30 \%$ of the Egyptians who cannot afford it. Enrollment in the scheme will be mandatory, with fees rated according to income with supplementary funding resources including taxes on polluting industries. The system will be initially adopted in five governorates and will be gradually implemented between 2018 and 2032 .

Keywords: SDG-3, Health, Hepatitis C, Insurance, Egypt

\section{Introduction}

\section{SDG-3: Good Health and Well-Being.}

By 2030 In Egypt, the UN Population Fund has forecast population to reach 119 million. UNICEF says about 3 in every 10 children suffer from multifactorial poverty including both poor health and education (Devi, 2018). In 2015, the world embraced the 2030 Sustainable Development Goals (SDGs), which seek to enhance the state of people's lives via 17 goals. Egypt's Vision 2030 (Egypt Sustainable Development Strategy (SDS))-the approved approach to tackle these goals-spans over economic, environmental and social dimensions. 8 goals are consistent with the pillars in Egypt's SDS including health (Egypt Ministry of Planning, Monitoring and Administrative Reform, 2016).

Egypt's SDS seeks to provide comprehensive health coverage for all via applying an integrated, high quality, and non-discriminatory health system that ensures financial support for vulnerable groups and the satisfaction of the workforce. Several national initiatives have been launched including (Egypt Ministry of Planning, Monitoring and Administrative Reform, 2018):

i. The National Committee for Combating Liver Diseases, to foster local treatment alternatives and ensure available and affordable medications. Egypt is the second highest country globally in terms of fatalities because of liver diseases.

The author is a Health Informatics Specialist and Public Health Researcher in Egypt. rayanr@alexu.edu.eg

https://www.gapcritique.in/egypt-towards-better-health-and-well-being/

Received 16 March 2019; Received in revised form 30 March 2019; Accepted 22 May 2019, Published 28 June 2019 
- The Social Health Insurance Law, which has been completed. Relevant entities are designing the application procedure including setting phases and the needed duration for application, in cooperation with public and private healthcare providing entities involving representatives of different syndicates.

\section{Egypt Steps towards Eradicating HCV}

In Egypt, the heavy HCV infection was precipitated by the mass treatment campaign using the intravenous (IV) antischistosomal injections from 1950 to 1980 (inadequately sterilized in-between use glass syringes that were also used in mass vaccination campaigns). HCV infection causes a life-compromising health burden for patients in the form of liver decompensation (cirrhosis), death/ transplantation, and hepatocellular carcinoma (HCC) (Centers for Disease Control and Prevention, 2012).

In 2015, the monetary load of HCV in Egypt was determined to be $\$ 3.81$ billion and the direct health care spending of $\mathrm{HCV}$ related conditions surpassed $\$ 700$ million annually. It is expected that the economic load will exponentially rise as the patients' progress to more severe levels of the disease. Early detecting and managing $\mathrm{HCV}$ patients is the aim of Egypt's treatment program targeting a reduction in $\mathrm{HCV}$ burden by $<2 \%$ in 10 years, parallel to global targets. Egypt seeks to treat 250,000 patients annually up to 2020 in the first phase of the program, consequently limiting the ongoing $\mathrm{HCV}$ transmission. With the availability of the new direct-acting antivirals (DAAs), Egypt is struggling to eradicate $\mathrm{HCV}$ by 2030 (Omran et al., 2018).

In 2006, The MOH established the National Committee for Control of Viral Hepatitis (NCCVH) for fighting HCV with the help of Hepatology and Public Health Professors (Egyptian and international experts). The NCCVH issued the national treatment strategy for managing $\mathrm{HCV}$ infection to eliminate $\mathrm{HCV}$ disease and develop an efficient infrastructure for the national treatment program activities (Egypt National Committee for the Control of Viral Hepatitis, 2008).

\section{a) HCV National Treatment Program in Egypt:}

The program infrastructure depended on building a large-scale network of specialized centers-reached 64 facilities in 2018- that offer integrated care for $\mathrm{HCV}$ patients, including screening, assessing patients eligibility for treatment, administrating of therapy, and following up during and after treatment by a well-trained multidisciplinary team. In 2010, the National Network for Treatment Centers was launched to enhance data management by linking the local centers to the main office in the National Hepatology Institute in Cairo (Omran et al., 2018).

The Ministry of Administrative Affairs established an online registration system. Online appointments were scheduled and automatically set to the nearest center to the patient. Scheduled lists were posted online and at the treatment centers. The Ministry of Communication contacted patients with short messaging service (SMS) and helplines were launched to answer patients' queries (Amer, 2018).

The mass HCV treatment program began by administering Pegylated interferon and ribavirin from 2007 to 2014. However, the response to such treatments was not satisfactory and was associated with several adverse events. In 2014, introducing sofosbuvir (Sovaldi ${ }^{\mathrm{TM}}$ ) evidently improved therapeutic outcomes. The main challenge was the great cost of the treatments, thus supplying these treatments free by the $\mathrm{MOH}$ or at a lower expanse was the principal attractor of patients to the program. The new DAAs was supplied at lower cost via negotiating the manufacturing companies allowing the treatment of a great number of patients in the first phase of the program, and the number increased to almost 150,000 patients in 3 years after introducing the locally produced DAAs. This massive national program introduced a great economic challenge to a resource-limited country like Egypt. The main funds for the program were the governmental support given to patients not covered with health insurance (Egypt Ministry of Health and Population, 2014).

\section{b) Preventive Measures (Egypt Ministry of Health and Population, 2014)}

Consolidating Surveillance: Until now, HCV vaccine does not exist. Most HCV-infected patients are unaware of being infected until they progress to hepatic cirrhosis. Each HCV patient can infect almost four subjects. The HCV centers leaded surveillance programs to detect HCV in various healthcare facilities. Screening programs can detect asymptomatic patients to enjoy early managing and counseling programs preserving their health and preventing further HCV spread in the community.

Boosting Infection Control Practices: HCV transmission is widely associated with a poor infection control practice during different medical interventions in Egypt. In 2002, MOH and international partners developed an organizational infection control (IC) program and guidelines, trained health care workers (HCWs), boosted occupational safety, and built a monitoring and evaluation system. 
IC program implementation enhanced infection control practice, HCWs compliance with a large decline in HCWs-induced HCV transmission.

Improving Blood Safety: Blood and related products' transfusion used to be a critical risk agent for HCV infection. In 1990, blood donor screening for $\mathrm{HCV}$ has almost eliminated this risk. Providers of blood transfusion services should implement strict precautions to ensure blood safety. In hemodialysis centers, HCV-infected patients should be assigned to separate hemodialysis units and HCWs should always wear protective gloves. Community Awareness Campaigns:

In Egypt, illiteracy was a risk element for $\mathrm{HCV}$ transmission, hence, health education about using personal equipment (as in shaving at barber shops), the single-use syringes and cleaning injection site, risks of Iv drugs and treating diagnosed patients; decreased HCV transmission and related complications. Recently, attempt to raise awareness about $\mathrm{HCV}$ via hotlines for counseling. Celebrating World Hepatitis Day brings all policy-makers and implementers together to send a relevant message to the public.

\section{Challenges for HCV Eradication}

In Egypt, budget scarcity is the main obstacle for HCV elimination, which lies in the costs of diagnosis and treatment. To achieve 2030 disease eradication target, the annual number of newly diagnosed patients must exceed 350,000/year along with a decline in the incidence of new patients by $>20 \%$. Infection Control is another obstacle to HCV elimination in Egypt.

Egypt remains in-need of formal IC programs in several healthcare facilities, trained HCWs and efficient equipment sterilization and reprocessing, and waste management. Controlling the ongoing HCV transmission in Egypt requires applying IC standards to all healthcare facilities beyond the $\mathrm{MOH}$ along with raising community awareness (Omran et al., 2018).

\section{Comprehensive Health Insurance Coverage in Egypt}

In 2018, the parliament has officially confirmed a new universal health coverage law in Egypt. This law is an update of the legacy one, which had been in place since the 1960s. The Universal Health Insurance Law (2/2018) will regulate the health sector, expanding comprehensive health coverage to all citizens. Previously, laws regulating healthcare were based on cases. For instance, law 99/1992 regulated students' healthcare and law 23/2012 regulated the breadwinners' women healthcare. The law proposes creating three bodies for upholding the system, aiming to protect the rights of vulnerable members of society. However, it imposes new financial obligations on business owners. Starting in 2018, law implementation will take place over six phases, ending in 2032. It will launch in five governorates, involving Port Said and Suez and will end with Giza and Cairo. Meanwhile the transition state, the current health insurance laws and regulations will remain operating. (Iskander, 2018).

Health services will be provided in three levels: Level-1 includes preventive measures and referrals, strengthening overall public health and halting disease transmission. Level-1 services will be offered via the primary healthcare units operated by family and general practitioners, diagnostic services, dentists and pharmacists. Level-2 includes diagnosis and treatment services and will be provided via accredited public and private hospitals, diagnostic and rehabilitation units. Level-3 includes rehabilitation services for special cases and will be provided via accredited public and private specialized centers and hospitals. Patients' conditions will be gradually managed through referrals from one level to another except for emergencies. The new system allows contracting with qualified private hospitals, police and army hospitals as long as they meet the accreditation requirements (Iskander, 2018).

The new health insurance law will be mandated by creating three bodies for funding, building, and supervising the implementation (Iskander, 2018):

The General Authority for Comprehensive Health Insurance supervised by the Prime Minister and headed in Cairo, with various branches all over Egypt. It will be collect the premiums from citizens, investing this money and using returns to finance the two other bodies. A committee for pricing medical services will be established including independent experts and specialists. It will fund the services by contracting healthcare providers, therapeutic services under the Healthcare Authority and other entities. It will identify the required service level for each patient allowing the patient to select the serving providers. It will enable patients to receive abroad healthcare services in case of the unavailability in Egypt.

The General Authority for Health Care supervised by the Minister of Health and will provide the three levels of healthcare via health units and general or specialized hospitals. The health units will provide family medicine, dentistry, pharmacy, pediatrics, obstetrics, emergency, and diagnostic services. providing the needed medicines and medical equipment. This authority will also build new hospitals, establishing bodies to manage health care providers, 
and An electronic health record for every family, with a sub-record for each member, will be created and kept with the assigned health unit. The record will include their medical history, health visits, and any used medications.

The General Authority for Accreditation and Supervision supervised by the President and will set quality standards for health units, hospitals, professionals, and accrediting the health facilities and providers complying with these standards. This authority will carry out routine inspections of the health facilities for an effective and transparent system along with cooperating and coordinating with peer international bodies.

\section{Financial Obligations and Penalties}

All the Egyptians living in Egypt will be mandatorily subscribed to the new health insurance system while being optional for those staying aboard. The government has committed to support the policy free to approximately $30 \%$ of the needy citizens. Contribution rates under the new law will be case-based and will be paid monthly starting from the implementation date of the new law in the relevant geographical area. Employees will pay a proportion of their income for their insurance, spouse and children depending on the number of children (Devi, 2018).

Business owners will pay an extra $4 \%$ of the total wage of the insured worker (3\% sickness insurance $+1 \%$ occupational injury). Other contributions will come from taxes on cigarettes \& cement industries, charges on marriage, birth, divorce and death certificates, fees for licensing cars or renewal of the driving license, and highway tolls for passing through various governorates. Moreover, all companies and establishments will contribute $0.25 \%$ of their annual gross revenues, non-deductible from the taxes. The law states that the plan will be reviewed every four years by experts allocating each body an independent budget for fulfilling their obligations. Again, the General Authority for Comprehensive Health Insurance will invest this money to use the returns for running the system (Iskander, 2018).

An additional annual amount will be mandated on citizens late in their payments. Furthermore, a penalty of at least 6 months jail period and/or a fine between 2,000 EGP and 100,000 EGP for anyone who incorrectly provides statements on duties paid under this law. Another penalty of at least 6 months jail period and a fine between 100,000 EGP and 200,000 EGP will be mandated on any employee of the authorities who assist subscribers in not paying their shares (Iskander, 2018).

\section{Implications of the New Law}

The scheme will be obligatory involving patients with significant conditions such as cancer and those on low incomes to be covered by the government. There will be separate roles for healthcare providers along with quality and

accreditation bodies. Patients will choose their own health care provider and facility. Following implementation, the law should eliminate patient waiting lists for surgeries and critical medical interventions within six months, securing required stock of infant formula and vaccines and accomplishing the massive screening and treatment of Hepatitis $\mathrm{C}$ for Egyptians (Hamdi, 2018).

\section{Challenges for the law implementation}

The State has confined up to $90 \%$ of the health insurance system's financial resources to the citizens while the government bears only $10 \%$ of the costs lifting the subsidy on healthcare services. Therefore, this project is expected to be financed out of the citizens' pockets and not the state's budget. The family head will mandatorily pay for the contributions of his/ her children until being employed (for males) or getting married (for females) and his/ her unemployed spouse; shifting the state's obligations towards the family and adding an extra burden over the family head (Hamdi, A, 2018).

Furthermore, the $0.25 \%$ mandated on businesses may seem unsubstantial; this percentage comes out of the gross and not their net revenues. This might impair small businesses from growing, causing more losses than gains. Moreover, this may discourage small businesses from formally registering their employees (Iskander, 2018).

\section{Conclusion}

The heavy burden of HCV infection in Egypt- the highest globally- boosted the launch of Egypt's pioneering experience against $\mathrm{HCV}$, seeking to eradicate HCV by 2030 . The strategic plan targeted both the treatment and prevention of new transmissions. Introducing DAAs is a cornerstone in HCV eradication plan. Preventing new transmissions is a real barrier that requires cooperation to raise population awareness about transmission modes, safe practices, and the importance of screening and early diagnosis. Fighting HCV presented a huge financial burden on Egypt, as it was difficult to secure funding sources to the $\mathrm{HCV}$ eradication program. Egypt provides a role model in planning and implementing the longterm goal of HCV eradication that can be adopted by other similar countries. 
Moreover, the new health insurance law is recognized as a significant step towards improving the current healthcare system in Egypt although concerns over funding means and its sustainability for the long and complicated implementation phases.

The gradual geographical implementation of the law is expected to cause complexities that will need to be managed by the Ministry of Health along with the ambiguities in calculating the contribution rates.

Furthermore, the new law will transfer financial commitment from the State to the individual and so ciety. Since the law is aimed at protecting vulnerable individuals, it should also account for small businesses allowing them to grow. Hence, by 2032, Egypt shall have a more comprehensive, accessible, and updated healthcare system but it could be made fairer for further technical modifications regarding the funding of the system.

\section{References}

Amer, F. A. (2018). Large-scale hepatitis C combating campaigns in Egypt and Georgia;

past, current and future challenges. The Journal of Infection in Developing Countries, 12(06), 404-414.

Centers for Disease Control and Prevention. (2012). Progress toward prevention and

control of hepatitis C virus infection-Egypt, 2001-2012. MMWR. Morbidity and mortality weekly report, 61(29), 545.

Devi, S. (2018). Universal health coverage law approved in Egypt. The Lancet,

391(10117), 194.
Egypt Ministry of Health and Population. (2014). Plan of Action for the Prevention,

Care \& Treatment of Viral Hepatitis, Egypt, 2014-2018

Egypt Ministry of Planning, Monitoring and Administrative Reform. (2018). Egypt's

Voluntary National Review 2018.

Egypt Ministry of Planning, Monitoring and Administrative Reform. (2016). Sustainable

Strategy: Egypt Vision 2030.

Egypt National Committee for the Control of Viral Hepatitis. (2008). Egyptian national

control strategy for viral hepatitis 20082012.

Hamdi, A. (2018). Egypt's Universal Health Insurance System. Egyptian Institute for

studies.

Iskander, M. (2018). Law No 2/2018 promulgating the Law on the Comprehensive

Health Insurance Scheme. Legal Alert 104. Retrieved from: https://andersentaxlegal.com.eg/legal-alert-104/

Omran, D., Alboraie, M., Zayed, R. A., Wifi, M. N., Naguib, M., Eltabbakh, M., ... \&

Saad, O. K. (2018). Towards hepatitis C virus elimination: Egyptian experience, achievements and limitations. World journal of gastroenterology, 24(38), 4330. 